HELMINTHOLOGIA, 54, $4 \cdot 2017$

\title{
EDITORIAL
}

\section{Milan Ryboš, DVM, D.Sc. (1936 - 2017)}

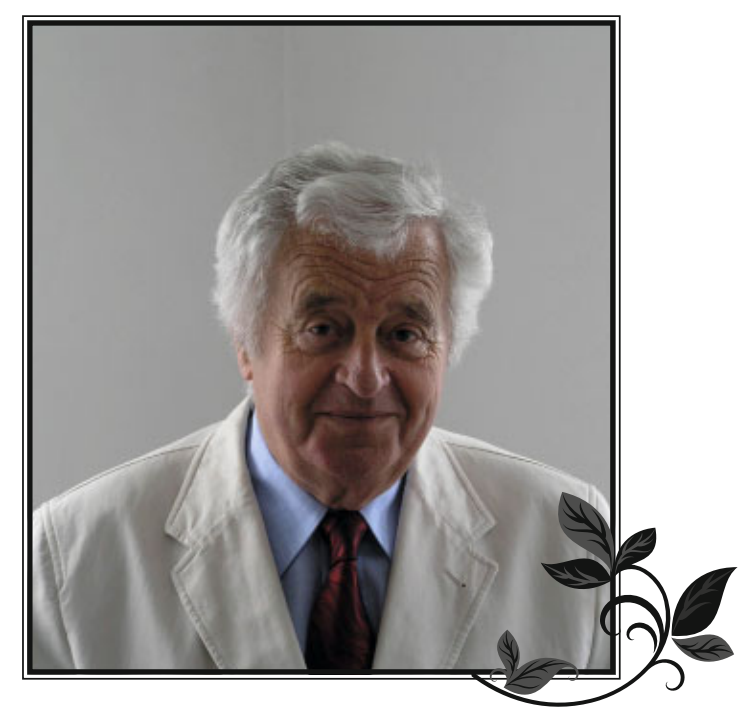

It is with great sadness that we announce the loss of Milan Ryboš, DVM, D.Sc., an outstanding scientist, colleague, and friend who passed away this summer at the age of 81. Dr. Ryboš served as Managing Editor for Helminthologia for the period of twelve years (1992 - 2004). For those of us who were lucky enough to know Milan personally it is difficult to believe that he is no longer with us.

Dr. Ryboš graduated from the University of Veterinary Medicine and Pharmacy in Košice, Slovakia in 1969. After that in 1978 he completed his $\mathrm{PhD}$ degree and become a respected member of the Institute of Parasitology of the Slovak Academy of Sciences. Here at the Institute his main research interests were focused particularly on biochemistry and physiology of helminths. Long term research activities focused on the adaptation of metabolic processes in parasitic nematodes resulted in successful defence of Doctor of Science title obtained in 1995.

Dr. Ryboš is appreciated for his work at the Helminthologia editorial office. He was always a good source of editorial advice and proficient in publication strategy. During his time as a managing editor and a reviewer, our journal has become listed in Current
Contents Connect as well as the other scientifically recognised databases. This significant improvement in publishing quality made our journal really international and attractive for domestic and foreign readership.

Dr. Ryboš was an outspoken advocate for helminthology as well as encouraging educator for junior scientists. He will be greatly missed as a colleague and friend. 